\title{
Comparison of Serum D-dimer, Fibrinogen and Platelet Levels in Pregnant Women with COVID-19 Symptoms According to PCR Positivity or PCR Negativity: A Case-Control Study
}

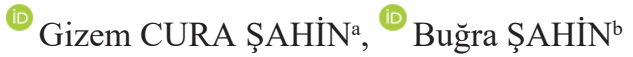 \\ ${ }^{a}$ Clinic of Gynecology and Obstetrics, Tokat State Hospital, Tokat, TURKEY \\ ${ }^{\mathrm{b}}$ Clinic of Gynecology and Obstetrics, Turhal State Hospital, Tokat, TURKEY
}

\begin{abstract}
Objective: The diagnosis and treatment of coronavirus disease-2019 (COVID-19) infection may be delayed in pregnant women because of the non-specific symptoms and limited application of the necessary radiological tests. The aim of this study was to compare the serum D-dimer, fibrinogen, and platelet levels in pregnant patients with COVID-19 symptoms and polymerase chain reaction (PCR) positivity or PCR negativity. Material and Methods: The study included 100 pregnant women who presented at the Gynaecology and Obstetrics Clinic of Tokat State Hospital between April 2020 and December 2020 with symptoms of COVID-19 infection (fever, cough, shortness of breath). Half of the patients were COVID-19 PCR positive and half were negative. The groups were compared in respect of age, gravida, gestational week, COVID-19 symptoms (fever, cough, shortness of breath), serum D-dimer, fibrinogen, and platelet values. Results: The serum D-dimer and fibrinogen levels were determined to be significantly higher in the PCR positive group than in the PCR negative group (1.78 \pm 1.04 $\mathrm{mg} / \mathrm{L}$ vs. $0.97 \pm 0.48 \mathrm{mg} / \mathrm{L}, \mathrm{p}=0.001$ and $348.02 \pm 84.69 \mathrm{~g} / \mathrm{mL}$ vs. $265.84 \pm 92.10 \mathrm{~g} / \mathrm{mL}, \mathrm{p}=0.001$, respectively). The complaints of cough and shortness of breath were determined to be significantly higher in the PCR positive group than in the PCR negative group ( $\mathrm{p}=0.001, \mathrm{p}=0.008)$. Conclusion: Routine measurements of serum D-dimer and fibrinogen levels in pregnant patients presenting with COVID-19 symptoms may be useful in early diagnosis and therefore an earlier start to treatment, without performing a COVID-19 PCR test. The presence of cough and shortness of breath in pregnant patients is more important than fever in the management of COVID-19 infection.
\end{abstract}

Keywords: COVID-19; D-dimer; fibrinogen; pregnancy; platelet

The novel coronavirus disease-2019 (COVID-19) caused by the severe acute respiratory syndrome-coronavirus-2 virus was declared a global pandemic by the World Health Organization on 11 March 2020. ${ }^{1}$ COVID-19 infection is spread through aerosol droplets or by direct contact, such as through the bodily fluids of the eye, nose, or mouth of another person, or an open cut, wound, or abrasion. ${ }^{2}$

Despite the new data obtained every day about the disease, information about the effects on the pregnant population remains limited. As pregnancy is a process with partial suppression of the immune system, women are left defence less against viral infections. Pregnant women are extremely sensitive to respiratory pathogens and severe pneumonia. A condition of intolerance to hypoxia develops together with elevated diaphragm, increased oxygen consumption, and oedema occurring in the respiratory tract mucosa. ${ }^{3}$ In a study of cases in 1918 , it was reported that the flu epidemic led to mortality rates of $2 \%-6 \%$ in the whole population and $37 \%$ in pregnant women. ${ }^{4}$ Even seasonal flu seen in the winter months increases morbidity rates in pregnancy. Therefore, the COVID-19 pandemic could cause serious health problems in pregnant women.

The clinical condition of pregnant women who contract COVID-19 pneumonia is similar to that of the

Correspondence: Gizem CURA ȘAHIN

Clinic of Gynecology and Obstetrics, Tokat State Hospital, Tokat, TURKEY

E-mail: drgizemcura@gmail.com

Peer review under responsibility of Journal of Clinical Obstetrics \& Gynecology.

Received: 21 Aug $2021 \quad$ Accepted: 23 Sep $2021 \quad$ Available online: 28 Sep 2021
2619-9467 / Copyright @ 2021 by Türkiye Klinikleri. This is an open
access article under the CC BY-NC-ND license (http://creativecommons.org/licenses/by-nc-nd/4.0/).


general population. ${ }^{5}$ However, because of the low numbers of cases in studies and the sensitivity of pregnant women to respiratory pathogens and severe pneumonia, it is necessary to maintain greater control of the process in pregnant women with COVID-19 infection. Therefore, pregnant women and newborns should be treated as a sensitive population in respect of the strategies and precautions used in the prevention of infection.

There is insufficient evidence related to the care of pregnant and breast-feeding women with COVID19, and limited data about the clinical condition and perinatal outcomes after infection. There is no evidence of pregnant women presenting with different signs and symptoms or of a more severe disease course. ${ }^{6}$ There is no definitive evidence of the transfer of infection from mother to infant in the third trimester with negative results obtained from the amniotic fluid, cord blood, vaginal discharge, maternal milk or from cultures from the throat of the infant. Similarly, there is insufficient evidence related to an increase in severe maternal or neonatal outcomes, and that infection is limited in the third trimester, but there are some reports of cases of early membrane rupture, fetal problems, and premature birth.,

The COVID-19 pandemic has increased concerns about pregnancy. It is very important that infection between pregnant patients is prevented and controlled. ${ }^{8}$ The aim of this study was to compare the serum Ddimer, fibrinogen, and platelet values in pregnant patients with COVID-19 symptoms and polymerase chain reaction (PCR) positivity or PCR negativity.

\section{MATERIAL AND METHODS}

A retrospective examination was made of the data of 100 pregnant women who presented at the Gynaecology and Obstetrics Clinic of Tokat State Hospital between April 2020 and December 2020 with symptoms of COVID-19 infection (fever, cough, shortness of breath). All procedures in this research were applied in compliance with the principles of the Helsinki Declaration 2008. Approval for the study was also obtained from the Turkish Ministry of Health. Of the 100 patients, 50 were COVID-19 positive in a PCR test and 50 were negative. The study subjects were pregnant women aged 18-45 years, in the range of 8-41 weeks of pregnancy. The study ex- clusion criteria were defined as active deep vein thrombosis, essential thrombocytopenia, or splenectomy. A record was made for each patient of age, gravida, gestational week, COVID-19 symptoms (fever, cough, shortness of breath), and serum Ddimer, fibrinogen, and platelet values at the time of presentation. The recorded parameters were compared between the 2 groups of those who were COVID-19 PCR test positive and those who were COVID-19 PCR test negative. Approval for the study was granted by the Tokat Gaziosmanpaşa University Faculty of Medicine Clinical Research Ethics Committee (date: 16.3.2021, no: 83116987-317). All patients provided informed consent.

PCR tests were applied to the pregnant patients with one or more of the complaints of fever, cough, or shortness of breath on presentation at the hospital. Diagnosis was made from quantitative reverse transcription-PCR (qRT-PCR) analysis of samples taken from the lower (more sensitive) and/or upper respiratory tract. For highly suspicious cases with a negative first test result, the test was repeated. If 2 qRT-PCR tests were negative, COVID-19 infection was discounted.

The American College of Radiology and the American College of Obstetricians and Gynecologists have started that, a single thoracic radiograph of a pregnant woman exposes the fetus to a negligible radiation dose of 0.0005-0.01 mGy, but as permission was not granted by any of the patients in this study, no chest X-rays were taken.

Treatment for the pregnant women was planned as the restoration of the fluid and electrolyte balance. To minimize maternal hypoxia, the oxygen saturation level was closely and carefully monitored. Arterial blood gas analysis was applied. Full blood count, kidney and liver function tests and clotting tests were regularly evaluated. If the gestational week was $\geq 26$, cardiotocography was performed to monitor the fetal heart rate, and when necessary, ultrasound devaluation of fetal growth and amniotic fluid volume was performed with umbilical artery Doppler. If the pregnancy was in earlier weeks, evaluation of amniotic fluid and fetal heart rate were accepted as sufficient. Paracetamol was used as anti-pyretic treatment, and low-dose fractioned enoxaparin was started as antithrombotic treatment. 


\section{STATISTICAL ANALYSIS}

Statistically analysis of the study data was made using SPSS vn. 22.0 software (SPSS Inc, Chicago, IL, USA). In the reporting of descriptive statistics, mean \pm standard deviation, median, minimum and maximum values were used for continuous variables and number and percentage for categorical variables. To determine statistically significant results and changes in rates between groups, the Student's t-test, Mann-Whitney U test, and chi-square test were used. The level of statistical significance was set at $p<0.05$.

\section{RESULTS}

The data of a total of 100 pregnant patients were analyzed. The PCR positive group $(n=50)$ had a mean age of $28.16 \pm 5.39$ years, mean gestational week of 22 (range, 8-41), and mean gravida of 2 (range, 1-5). The PCR negative group $(\mathrm{n}=50)$ had a mean age of $29.6 \pm 5.83$ years, mean gestational week of 34 (range, 10-41), and mean gravida of 2 (range, 1-5). No significant difference was determined between the groups in respect of age, gestational week, and gravida $(p=0.293$, $\mathrm{p}=0.097, \mathrm{p}=0.660$, respectively) (Table 1 ).

The D-dimer levels of the pregnant patients were determined to be $1.78 \pm 1.04 \mathrm{mg} / \mathrm{L}$ in the $\mathrm{PCR}$ positive group and $0.97 \pm 0.48 \mathrm{mg} / \mathrm{L}$ in the PCR negative group. The serum fibrinogen levels were determined to be $348.02 \pm 84.69 \mathrm{~g} / \mathrm{mL}$ in the PCR positive group and $265.84 \pm 92.1 \mathrm{~g} / \mathrm{mL}$ in the PCR negative group. The serum $\mathrm{D}$-dimer and fibrinogen values were determined to be statistically significantly higher in the PCR positive group than in the PCR negative group $(p=0.001$, $\mathrm{p}=0.001$ ). No statistically significant difference was determined between the groups in respect of the serum platelet value; PCR positive: $240.36 \pm 79.35$, and PCRnegative: $255.22 \pm 72.51(\mathrm{p}=0.387)$ (Table 1).

The complaint of fever was observed in 37 (74\%) of the PCR positive group and in $31(62 \%)$ of the PCR negative group. Cough was observed in 42 (84\%) of the PCR positive group and in $30(60 \%)$ of the PCR negative group. Shortness of breath was observed in $16(32 \%)$ of the PCR positive group and in 2 (4\%) of the PCR negative group. The COVID-19 symptoms of cough and shortness of breath were determined at a statistically significantly higher rate in the PCR positive group than in the PCR negative group $(\mathrm{p}=0.008, \mathrm{p}=0.001)$ and fever was observed at similar rates in the 2 groups $(\mathrm{p}=0.198)$ (Figure 1$)$.

\section{DISCUSSION}

In this single-centre study over a 9-month period, 50 pregnant women with PCR test positivity for COVID19 infection and 50 pregnant women with a negative PCR test were examined and the results demonstrated that the serum D-dimer and fibrinogen levels were significantly higher in the COVID-19 positive patients. Of the clinical complaints of COVID-19, there was also seen to be a higher rate of cough and shortness of breath rather than fever in the pregnant patients with a positive PCR test for COVID-19.

\begin{tabular}{|c|c|c|c|}
\hline & PCR test positive $(n=50)$ & PCR test negative $(n=50)$ & $p$ value \\
\hline Age (years) & $28.16 \pm 5.39$ & $29.6 \pm 5.83$ & 0.293 \\
\hline Gestational week & $22(8-41)$ & $34(10-41)$ & 0.097 \\
\hline Gravida & $2(1-5)$ & $2(1-5)$ & 0.660 \\
\hline D-dimer (mg/L) & $1.78 \pm 1.04$ & $0.97 \pm 0.48$ & $0.001^{*}$ \\
\hline Fibrinogen (g/mL) & $348.02 \pm 84.69$ & $265.84 \pm 92.1$ & $0.001^{*}$ \\
\hline Platelet & $240.36 \pm 79.35$ & $255.22 \pm 72.51$ & 0.387 \\
\hline Fever & $37(74 \%)$ & $31(62 \%)$ & 0.198 \\
\hline Cough & $42(84 \%)$ & $30(60 \%)$ & $0.008^{*}$ \\
\hline Shortness of breath & $16(32 \%)$ & $2(4 \%)$ & $0.001^{*}$ \\
\hline
\end{tabular}

Variables presented as mean \pm standard deviation, median (minimum-maximum) and $\mathrm{n}$ and \%; PCR: Polymerase chain reaction.

*; the level of statistical significance was set at $p<0.05$. 


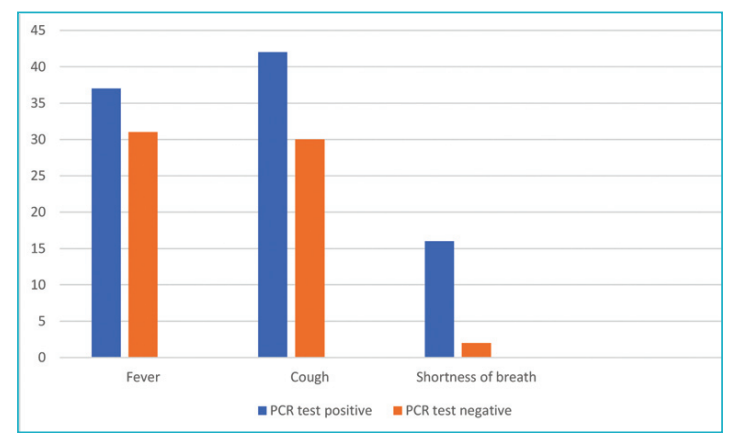

FIGURE 1: The distribution of the COVID-19 symptoms in the pregnant women according to the PCR test results.

PCR: Polymerase chain reaction.

Pregnant women are extremely sensitive to respiratory pathogens and severe pneumonia. Even seasonal flu seen in the winter months can increase morbidity rates in pregnancy. Therefore, the COVID19 pandemic may cause severe health outcomes in pregnant women. With the spread of COVID-19 throughout the world, the concerns about pregnant patients have increased. As yet there is insufficient evidence in respect of the clinical strategies and effective protective methods required for the prevention and control of the infection in pregnant women. ${ }^{9}$ In the upper respiratory tract infections caused by COVID-19, just as in other viral infections, non-specific symptoms may be seen such as fever, cough, sore throat, muscle pain, listlessness, loss of appetite, dyspnea and nasal blockage. Atypical symptoms are seen in patients with weak immune systems such as the elderly and pregnant women. Diagnosis of the disease may be delayed during pregnancy as the symptoms frequently seen in COVID-19 infection, such as fatigue, loss of appetite, and dyspnea are seen physiologically in pregnancy. ${ }^{10,11}$ In the current study, the COVID-19 complaints of cough and shortness of breath were seen at higher rates than fever in the pregnant patients with a positive PCR test.

Leukopenia, leukocytosis, and lymphopenia have been reported in patients with COVID-19, and of these, lymphopenia is seen most often. Elevated lactate dehydrogenase and ferritin levels are common and high aminotransferase levels have also been reported. Normal serum procalcitonin levels on presentation may be seen in some patients with pneumonia, but there is a possibility of higher levels in those requiring intensive care. High D-dimer levels and severe lym- phopenia have been associated with mortality. ${ }^{12} \mathrm{Co}-$ agulopathy originates from the simultaneous activation of clotting and fibrinolitic stages, probably triggered by sepsis, and causing consumption of the clotting factor. Coagulation may be thrombotic or hemorrhagic. When it is considered that pregnancy is a condition with physiologically increased clotting, an increase in the third trimester of $>50 \%$ over the baseline of clotting factors such as fibrinogen and D-dimer adds to the complexity. ${ }^{13}$ In a previous study that examined 108 pregnant women with COVID-19, it was reported that $68 \%$ presented with fever and $34 \%$ with cough in the third trimester. ${ }^{14}$ Another study found a significant relationship between COVID-19 in pregnancy and symptoms such as fever, cough, shortness of breath, and anosmia. ${ }^{15}$ When it is considered that elevated $\mathrm{D}$-dimer levels are typical in pregnancy, it remains uncertain which cut-off value shows a poor prognosis. ${ }^{13}$ Other than those who are pregnant, the anticoagulation results of coagulopathic, septic patients improve. ${ }^{16}$ The current study results showed that the serum D-dimer levels were statistically significantly higher in the group with PCR positivity compared to those negative PCR test.

In 2 guidelines that deal with coagulopathy in COVID-19, it is emphasized that elevated D-dimer, thrombocytopenia, and low fibrinogen are markers of poor prognosis for the risk of mortality. ${ }^{17,18}$ While low fibrinogen in pregnancy is the only clotting parameter associated with the severity of postpartum hemorrhage, fibrinogen $<2 \mathrm{~g} / \mathrm{L}$ has been shown to be related to COVID-19 with $100 \%$ positive predictive value. ${ }^{19}$ In all patients presenting with COVID-19, routine measurements of D-dimer, prothrombin time and platelet counter is helpful in risk classification. The measurement of activated partial thromboplastin time and fibrinogen levels may be of value in pregnancy. ${ }^{20}$ The current study results showed significantly higher levels of serum fibrinogen in the pregnant patients with PCR positivity for COVID-19 infection compared to the PCR negative group. However, the same was not determined for serum platelet values.

This study had some limitations, primarily the retrospective examination of patient files rather than the collection and analysis of current data. The low number of patients in both groups could have been 
the reason that significant results were not reached in the comparisons of some parameters. Therefore, further prospective studies with a greater number of patients are still required.

\section{CONCLUSION}

In conclusion, it can be seen from the results of this study that the levels of serum D-dimer and fibrinogen were higher in pregnant patients with COVID19 symptoms and a positive PCR test result compared to those who tested PCR negative for COVID-19 infection. Therefore, routine measurements of serum D-dimer and fibrinogen levels in all pregnant patients presenting with COVID-19 symptoms may be useful for risk classification in respect of COVID-19 positivity and an early start to treatment. Furthermore attention paid to cough and shortness of breath rather than fever in pregnant patients could accelerate the management of COVID-19 infection.

\section{Source of Finance}

During this study, no financial or spiritual support was received neither from any pharmaceutical company that has a direct connection with the research subject, nor from a company that provides or produces medical instruments and materials which may negatively affect the evaluation process of this study.

\section{Conflict of Interest}

No conflicts of interest between the authors and / or family members of the scientific and medical committee members or members of the potential conflicts of interest, counseling, expertise, working conditions, share holding and similar situations in any firm.

\section{Authorship Contributions}

All authors contributed equally while this study preparing.

\section{REFERENCES}

1. World Health Organization. Coronavirus disease (COVID-19) technical guidance: Surveillance and case definitions. Geneva: World Health Organization. 2020. Date of access:2 April 2020. [Link]

2. Huang $\mathrm{C}$, Wang $\mathrm{Y}, \mathrm{Li} \mathrm{X}$, Ren L, Zhao J, Hu Y, et al. Clinical features of patients infected with 2019 novel coronavirus in Wuhan, China. Lancet. 2020;395(10223):497-506. Erratum in: Lancet. 2020. [Crossref] [Pubmed] [PMC]

3. Tetikkurt C. Gebelikte solunum fizyolojisi [Respiratory physiology in pregnancy]. Cerrahpaşa J Med. 2000;31(2):118-22. [Link]

4. Gottfredsson M. Spaenska veikin á Islandi 1918. Laerdómur í laeknisfraedi og sögu [The Spanish flu in Iceland 1918. Lessons in medicine and history]. Laeknabladid. 2008;94(11): 737-45. Icelandic. [Pubmed]

5. Qiao J. What are the risks of COVID-19 infection in pregnant women? Lancet. 2020;395(10226): 760-2. [Crossref] [Pubmed] [PMC]

6. Chen H, Guo J, Wang C, Luo F, Yu X, Zhang $W$, et al. Clinical characteristics and intrauterine vertical transmission potential of COVID19 infection in nine pregnant women: a retrospective review of medical records. Lancet. 2020;395(10226):809-15. Erratum in: Lancet. 2020;395(10229):1038. Erratum in: Lancet. 2020;395(10229):1038. [Crossref] [Pubmed] [PMC]

7. Özcan H, Elkoca A, Yalçın Ö. COVID-19 Enfeksiyonu ve Gebelik Üzerindeki Etkileri.
Anadolu Klin. 2020;25(Special Issue on COVID 19):43-50. [Crossref]

8. Dashraath P, Wong JLJ, Lim MXK, Lim LM, Li S, Biswas A, et al. Coronavirus disease 2019 (COVID-19) pandemic and pregnancy. Am J Obstet Gynecol. 2020;222(6):521-31. [Crossref] [Pubmed] [PMC]

9. Benedetti TJ, Valle R, Ledger WJ. Antepartum pneumonia in pregnancy. Am J Obstet Gynecol. 1982;144(4):413-7. [Crossref] [Pubmed]

10. Boldog P, Tekeli T, Vizi Z, Dénes A, Bartha FA, Röst $\mathrm{G}$. Risk assessment of novel coronavirus COVID-19 outbreaks outside China. J Clin Med. 2020;9(2):571. [Crossref] [Pubmed] [PMC]

11. Dhama K, Khan S, Tiwari R, Sircar S, Bhat S, Malik YS, et al. Coronavirus disease 2019COVID-19. Clin Microbiol Rev. 2020;33(4): e00028-20. [Crossref] [Pubmed] [PMC]

12. Uzel K, Lakhno I. PCR positivity and D-dimer levels in pregnant women with COVID-19. Clinical and Experimental Obstetrics \& Gynecology. 2020;47(5):638-44. [Crossref]

13. Abbassi-Ghanavati M, Greer LG, Cunningham FG. Pregnancy and laboratory studies: a reference table for clinicians. Obstet Gynecol. 2009;114(6):1326-31. Erratum in: Obstet Gynecol. 2010;115(2 Pt 1):387. [Crossref] [Pubmed]

14. Zaigham M, Andersson O. Maternal and perinatal outcomes with COVID-19: A systematic review of 108 pregnancies. Acta Obstet Gynecol Scand. 2020;99(7):823-9. [Crossref] [Pubmed] [PMC]
15. Ruggiero M, Somigliana E, Tassis B, Piani LL, Renteria SU, Barbara G, et al. COVID-19 in the second half of pregnancy: prevalence and clinical relevance. Research Square. 2020. [Crossref]

16. Eljilany I, Elzouki AN. D-dimer, fibrinogen, and IL-6 in COVID-19 patients with suspected venous thromboembolism: a narrative review. Vasc Health Risk Manag. 2020;16:455-62. [Crossref] [Pubmed] [PMC]

17. Thachil J, Tang N, Gando S, Falanga A, Cattaneo M, Levi M, et al. ISTH interim guidance on recognition and management of coagulopathy in COVID-19. J Thromb Haemost. 2020;18(5):1023-6. [Crossref] [Pubmed]

18. Zhu N, Zhang D, Wang W, Li X, Yang B, Song $\mathrm{J}$, et al; China Novel Coronavirus Investigating and Research Team. A novel coronavirus from patients with pneumonia in China, 2019. N Engl J Med. 2020;382(8): 727-33. [Crossref] [Pubmed] [PMC]

19. Hellewell J, Abbott S, Gimma A, Bosse NI, Jarvis $\mathrm{Cl}$, Russell TW, et al. Feasibility of controlling COVID-19 outbreaks by isolation of cases and contacts. Lancet Glob Health. 2020;8(4):e488-96. Erratum in: Lancet Glob Health. 2020. [Crossref] [Pubmed] [PMC]

20. Vlachodimitropoulou Koumoutsea E, Vivant AJ, Shehata N, Benachi A, Le Gouez A, Desconclois C, et al. COVID-19 and acute coagulopathy in pregnancy. J Thromb Hae most. 2020;18(7):1648-52. [Crossref] [Pubmed] 